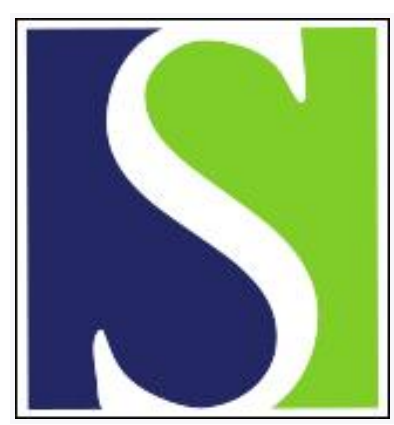

Scand J Work Environ Health 1994;20(4):279-285

https://doi.org/10.5271/sjweh.1397

Issue date: 01 Aug 1994

Internal load of aluminum and the central nervous system function of aluminum welders.

by Hanninen H, Matikainen E, Kovala T, Valkonen S, Riihimaki V

Affiliation: Department of Occupational Medicine, Finnish Institute of Occupational Health, Helsinki.

This article in PubMed: www.ncbi.nlm.nih.gov/pubmed/7801073

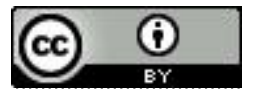




\title{
Internal load of aluminum and the central nervous system function of aluminum welders
}

\author{
by Helena Hänninen, PhL, ${ }^{1}$ Esko Matikainen, MD, ${ }^{2}$ Tero Kovala, MD, ${ }^{2}$ \\ Sinikka Valkonen, BSc(Eng), ${ }^{3}$ Vesa Riihimäki, $\mathrm{MD}^{3}$
}

\begin{abstract}
HÄNNINEN H, MATIKAINEN E, KOVALA T, VALKONEN S, RIIHIMÄKI V. Internal load of aluminum and the central nervous system function of aluminum welders. Scand $J$ Work Environ Health 1994;20:279-85.
\end{abstract}

\begin{abstract}
OBJEctives - Because the brain is the recognized target organ for aluminum toxicity, internal aluminum load and central nervous system functions were investigated among aluminum welders in a shipyard.

METHons - Seventeen male welders with a mean age of 37 (range 24-48) years and a history of about four years of metal inert-gas welding on aluminum were the subjects. Aluminum in serum (S-Al) and urine (U-Al) was analyzed with graphite-furnace atomic absorption spectrophotometry. Central nervous system functions were examined with neuropsychological tests, symptom and mood questionnaires, quantitative electroencephalography (QEEG), and P300 evoked responses.

Resulrs - The mean S-Al concentration was 0.21 (range $0.03-0.64$ ) $\mu \mathrm{mol} \cdot \mathrm{l}^{-1}$ and the mean $\mathrm{U}-\mathrm{Al}$ was 2.8 (range $0.9-6.1$ ) $\mu \mathrm{mol} \cdot \mathrm{l}^{-1}$. Although the welders performed normally on the neuropsychological tests, there was a negative association between all four memory tests and U-Al and a positive association between the variability of visual reaction times and S-Al. In the QEEG, the amount of delta and theta activity in the frontal region correlated positively and the amount of alpha activity in the frontal region correlated negatively with S-Al.

Conclusions - The $\mathrm{S}-\mathrm{Al}$ and $\mathrm{U}-\mathrm{Al}$ measurements indicated increased internal loads of aluminum in most of the welders. This finding is compatible with slowly eliminated aluminum from tissues. The neuropsychological assessment suggested disturbing effects of aluminum on short-term memory, learning, and attention. In the QEEG, a corresponding exposure-effect relationship was found for activity in the frontal region. Further studies are needed on the possibility that exposure to aluminum welding fumes causes harm to human health.
\end{abstract}

KeY TERMs - neuropsychological effects, quantitative electroencephalography, serum and urinary aluminum,

The neurotoxicity of aluminum came to light in the context of dialysis encephalopathy caused by the accumulation of aluminum in the brain of patients. The syndrome is characterized by speech disturbances, seizures, and a decline in cognitive function (1). A slight decline in psychological test performances has also been observed in hemodialysis patients with mildly raised serum aluminum and apparently normal cerebral functioning (2).

Aluminum-induced degenerative changes in the brain of experimental animals have been well documented $(3,4)$. They include encephalomyelopathy, brain-stem demyelination, and the development of neurofibrillary tangles. At the behavioral level, im-

Maskuntie 3 A, FIN-00280 Helsinki, Finland.

2 Department of Occupational Medicine, Finnish Institute of Occupational Health, Helsinki, Finland.

3 Department of Industrial Hygiene and Toxicology, Finnish Institute of Occupational Health, Helsinki, Finland.

Reprint requests to: Dr V Riihimäki, Department of Industrial Hygiene and Toxicology, Finnish Institute of Occupational Health, Topeliuksenkatu 41 a A, FIN-00250 Helsinki, Finland. paired learning, retention, and motor coordination have been described. Similarities between aluminuminduced changes and changes found in Alzheimer's disease have given rise to numerous studies dealing with the possible etiologic role of aluminum in Alzheimer's disease and certain other dementing diseases of the central nervous system (CNS) (1). However, recent research has also shown essential biochemical differences between these two conditions (4).

In spite of the wide interest in aluminum neurotoxicology since the late 1970 s, only a few studies have addressed the question of possible neurobehavioral effects of occupational exposure to low concentrations of aluminum. In a study of miners who inhaled aluminum in the form of McIntyre powder, Rifat and others (5) found cognitive impairments, some of which were related to the duration of exposure. Two other reports $(6,7)$ have described the neuropsychological syndrome in aluminum foundry and smelter workers. Although each of these studies had methodological weaknesses, they nevertheless suggest that even rather moderate long-term exposures to aluminum may involve hazards to CNS function. 
Our study deals with a small group of aluminum welders. The objectives were to describe the level of aluminum exposure in this group and to evaluate the neurotoxic health hazards. A detailed description of the exposure situation will be given elsewhere (Riihimäki et al, in preparation). This paper reports the neurophysiological and neuropsychological results.

\section{Subjects and methods}

\section{Subjects}

The subjects were 17 male aluminum welders from a ship building company. Their mean age was 36.6 (range 24-48) years. Their education consisted of the customary comprehensive school (elementary and junior high school) with or without vocational schooling of one or two years.

\section{Work history and exposure to aluminum}

The subjects had been engaged in welding for 527 (mean 15) years but had been metal inert-gas welding on aluminum for only about the last four years. They generally considered work with aluminum both more demanding and more rewarding than work with other metals. According to the interview the workers mostly carried respiratory protection that ventilated the welding masks with filtered or pressurized air while welding, but a few admitted that they did not use respiratory protection regularly when working in enclosed spaces.

\section{Parameters of aluminum exposure}

For 11 of the welders the aluminum concentrations in urine (U-Al) and serum (S-Al) had been analyzed in samples taken some months earlier during a survey of the exposure conditions in the shipyard. The S-Al parameter used in this study was determined from the morning sample taken before the work shift. The U-Al parameter was the mean of four weekly urine samples taken during the summer vacation. For the other six subjects, the serum and urine samples were taken on the morning of the examination day.

The S-Al and U-Al concentrations were analyzed with a graphite furnace atomic absorption spectrophotometer with Zeeman background correction and an automatic sampler (8), and they were based on a fourfold dilution of serum and urine with $0.07 \%$ nitric acid and on analysis with the platform technique in pyrolytically coated graphite tubes. For the serum analysis matrix-matched standard curves were prepared, and, correspondingly, for the urine analysis the method of standard addition was used.

The day-to-day coefficient of variation was $6 \%$ for serum and $7.2 \%$ for urine at a concentration level of $4.0 \mu \mathrm{mol} \cdot \mathrm{I}^{-1}$. The detection limits of aluminum were $0.02 \mu \mathrm{mol} \cdot \mathrm{l}^{-1}$ for serum and $0.07 \mu \mathrm{mol} \cdot \mathrm{l}^{-1}$ for urine. Special efforts were made to avoid contamination in all steps of the procedure.
Each analytical run included an analysis of a reference sample: Seronorm Trace Elements Serum No 2107 (Nycomed, Norway) for serum and Lyphocheck Control Urine 1 (Bio-Rad ECS Division, California, United States) for urine.

The laboratory participated regularly in two external quality assurance programs for aluminum in serum, the scheme of the Robens Institute, Guildford, England, and the scheme of Le Centre de Toxicologie du Quebec, Canada.

\section{Neuropsychological methods}

The neuropsychological tests included the simple reaction time test, three tests for psychomotor speed (finger tapping, Santa Ana and digit symbol), two tests for visual and spatial ability (block design and embedded figures), four memory tests (symbol learning, memory-for-design, digit span and associative learning), and two tests for verbal ability (similarities and synonyms).

Simple reaction time and finger tapping speed were measured by computerized tests from the Swedish Performance Evaluation System (9). The other tests have been described in reference 10 . The test series was given in a standard manner and always at the same time of day. The scoring of the embedded figures, memory-for-design, and similarities tests was carried out blindly by two independent psychologists. On the singular occasions of discrepancy a consensus decision was easily reached.

\section{Subjective symptoms and moods}

Disturbances in subjective well-being were assessed with the aid of a symptom questionnaire with six separate symptom scales, and by the Finnish version of the Profile of Mood States (POMS) inquiry. Scales with high mutual correlation were combined in the data analysis as follows: the sum scale for $f a-$ tigue consisted of corresponding scales of the symptom questionnaire and the POMS, the sum scale of memory problems of the corresponding symptom questionnaire and POMS scales, tension-irritability of the POMS scales tension and hostility, and $d e-$ pression of the POMS scales depression and helplessness. The other scales of the symptom questionnaire included sleep disturbances, emotional instability, somatic complaints, and sensory and motor symptoms.

\section{Neurological interview}

In the neurological interview, past and present diseases and subjective symptoms were asked about. All of the major disease categories were individually inquired about. The symptom inquiry consisted mainly of neuropsychiatric symptoms, such as memory disturbances, concentration, cognitive functions, tremor, disturbances in coordination, sensory disturbances, headache, vertigo, and dizziness. 


\section{Quantitative electroencephalography}

The quantitative electroencephalography (QEEG) recording was done in a dim room while the subjects sat in a comfortable chair with their eyes closed, but being reminded to stay awake. The electrodes were unpolarized silver-silver chloride surface electrodes, which were placed according to the international $10-20$ system. In addition, $F_{p z}$ (between $\mathrm{F}_{\mathrm{p} 1}$ and $\mathrm{F}_{\mathrm{p} 2}$ ) and $\mathrm{O}_{\mathrm{z}}$ (between $\mathrm{O}_{1}$ and $\mathrm{O}_{2}{ }^{\mathrm{pz}}$ ) electrodes were used. The recording was performed with Cadwell Spectrum 32 equipment. The electroencephalography (EEG) was recorded with 21 channels. The signal was filtered with the use of a 70 $\mathrm{Hz}$ low-pass filter, and, in addition, a $50-\mathrm{Hz}$ notch filter was used. The sampling frequency of the analogue digital transformation was $205 \mathrm{~Hz}$. The visual interpretation, choice of epochs, and quantitative analyses were later done with a Cadwell RDC-32 reading station. For the quantitative analysis, 2448 (mean 42.6, SD 7.6) epochs lasting $2.5 \mathrm{~s}$ each were gathered $(1-2 \mathrm{~min})$. The chosen epochs had to be artifact-free and without signs of a lowered level of vigilance in the EEG or electrooculography channels during the recording. Two recordings had to be abandoned because 24 epochs fulfilling the criteria could not be found.

Quantitative analyses were made within the frequency band of $1.5-20 \mathrm{~Hz}$ with the Neurometrics program of the Cadwell RDC-32 equipment. The analyzed frequency band was divided into the delta band $(1.5-3.5 \mathrm{~Hz})$, theta band $(3.5-7.5 \mathrm{~Hz})$, alpha band $(7.5-12.5 \mathrm{~Hz})$, and beta band $(12.5-20.0 \mathrm{~Hz})$. In monopolar montages $\left(\mathrm{A}_{1} \mathrm{~A}_{2}\right.$ as reference), absolute and relative power values were analyzed in the aforementioned bands in all 21 channels. The mean frequencies within the whole $1.5-20 \mathrm{~Hz}$ frequency band was analyzed in all channels.

The number of variables was reduced in calculations of the regional means from the original variables as follows:

Region

Frontal region

Temporal region

Centroparietal region

Occipital region

After the aforementioned calculations there were 36 EEG variables (16 for absolute power, 16 for relative power, and 4 for mean frequencies).

\section{P300 evoked responses}

The subjects were examined while awake, eyes closed, and sitting in a comfortable chair. Tones were presented binaurally at a sound pressure level of $70 \mathrm{~dB}$ with a $10-\mathrm{ms}$ rise time, a $30-\mathrm{ms}$ plateau time, and a $10-\mathrm{ms}$ fall time. The stimulation frequency was $0.50-0.58 \mathrm{~Hz}$. The standard tone frequency was $1000 \mathrm{~Hz}$, and the target tone frequency was $2000 \mathrm{~Hz}$. Two 256-trial blocks were presented, each contain- ing $64(25 \%)$ target stimuli in random order. The subjects were instructed to count the number of the $2-\mathrm{kHz}$ targets. Activity was recorded at the $\mathrm{C}_{\mathrm{z}}$ and $\mathrm{P}_{z}$ electrode sites of the $10-20$ international system using nonpolarizing silver-silver chloride electrodes, referred to linked earlobes, all electrodes being affixed with electrode paste and having impedances less than $10 \mathrm{k} \Omega$. The filter bandpass was $0.5-70 \mathrm{~Hz}$. The analysis time was $650 \mathrm{~ms}$, including a $50-\mathrm{ms}$ prestimulus base line. Waveforms were averaged online by a commercial apparatus (Cadwell Spectrum 32 ), which also controlled the stimulus presentation. Latencies and amplitudes were measured afterwards. At first, the mean responses were formed from the two original responses. A difference response was formed concerning the $\mathrm{P}_{\mathrm{z}}$ channel by subtracting the standard mean response from the target mean response. The latencies and amplitudes of the P300 wave were measured from the mean responses to the target stimuli in both channels, and from the difference response. In the amplitude measurements, the prestimulus base line was used as the reference level.

\section{Statistical methods}

Associations between the exposure parameters and the psychological or neurophysiological measures were examined by Spearman's rank-order correlations. For the age-dependent neurophysiological variables partial correlations with control for age were applied.

\section{Results}

\section{Exposure to aluminum}

The U-Al concentrations ranged from 0.9 to 6.1 (median 2.4 , mean 2.8$) \mu \mathrm{mol} \cdot 1^{-1}$. The S-Al concentrations ranged from 0.03 to 0.64 (median 0.18 , mean $0.21) \mu \mathrm{mol} \cdot \mathrm{l}^{-1}$. The correlation with age was -0.28 for $\mathrm{U}-\mathrm{Al}$ and 0.10 for $\mathrm{S}-\mathrm{Al}$.

\section{Neuropsychological tests}

The mean scores of the tests for psychomotor, visual, and spatial abilities in our group fell within the good-average range, and the means of the memory tests and tests for verbal ability were within the average range, according to unpublished standardization data of the Finnish Institute of Occupational Health that were gathered in the context of previous epidemiologic studies involving skilled and semiskilled chemically exposed workers and workers with slight neurotoxic exposure.

However, correlations between the test scores and exposure parameters showed a negative association between the four memory tests and exposure to aluminum and a positive association between the variability (standard deviation) of visual reaction times and exposure (table 1). For the memory tests, the statistically significant associations were with U-AL, 
and for reaction time variation the statistically significant association was with S-Al. The correlations of these test parameters with age were low, below 0.20 for the memory tests and 0.29 for the variability of the reaction times.

The other test parameters were not associated with the exposure.

\section{Subjective symptoms and moods}

Compared with the reference material, the mean scores for all of the symptom and mood scales were low, but the standard deviations were large. Half of the subjects had zero or near-to-zero scores in almost all of the symptom and mood scales. A few had elevated scores. Low scores for the combined symptom and mood scores were associated with a high S-Al (table 2). Nine of the 10 welders with an S-Al level

Table 1. Correlations of the scores for four memory tests and the variability of the visual reaction times with measures of aluminum body burden ( $N=17)$. (U-Al = aluminum level in urine, $\mathrm{S}-\mathrm{Al}=$ aluminum level in serum)

\begin{tabular}{lcc}
\hline & U-AI & S-Al \\
\cline { 2 - 3 } Memory-for-design & $-0.57^{* *}$ & -0.30 \\
Symbol learning & $-0.48^{\star}$ & -0.23 \\
Digit span & $-0.46^{\star}$ & -0.21 \\
Associative learning & $-0.50^{\star \star}$ & -0.33 \\
Visual reaction times, & 0.34 & $0.66^{\star \star *}$ \\
standard deviation & 0.4 \\
\hline
\end{tabular}

${ }^{\star} \mathrm{P}<0.1,{ }^{* \star} \mathrm{P}<0.05,{ }^{* * *} \mathrm{P}<0.01$.

Table 2. Correlations between measures of aluminum body burden and four symptom or mood scales $(N=17)$. (U-AI $=$ aluminum level in urine, $\mathrm{S}-\mathrm{Al}=$ aluminum level in serum)

\begin{tabular}{lrl}
\hline & U-AI & \multicolumn{1}{c}{ S-Al } \\
\cline { 2 - 3 } Fatigue & 0.07 & $-0.56^{\star *}$ \\
Memory & -0.21 & $-0.45^{\star}$ \\
Depression & -0.03 & -0.35 \\
Tension or irritability & -0.36 & $-0.76^{\star * *}$ \\
\hline
\end{tabular}

* $P<0.01,{ }^{* *} P<0.05,{ }^{* * *} P<0.01$.

Table 3. Correlations of absolute and relative power values of quantitative electroencephalography (QEEG) in the frontal region with measures of aluminum body burden $(N=15)$. (U.AI = aluminum level in urine, $\mathrm{S}-\mathrm{Al}=$ aluminum level in serum)

\begin{tabular}{lcc}
\hline QEEG parameter & U-AI & S-AI \\
\hline Absolute power & & \\
Delta band & 0.10 & 0.31 \\
Theta band & 0.03 & 0.28 \\
Alpha band & -0.38 & $-0.58^{\star *}$ \\
Beta band & -0.24 & -0.06 \\
Relative power & & \\
Delta band & 0.42 & $0.48^{\star}$ \\
Theta band & 0.31 & $0.75^{\star \star *}$ \\
Alpha band & $-0.48^{*}$ & $-0.72^{\star \star *}$ \\
Beta band & 0.22 & $0.57^{\star *}$ \\
\hline$*$ & &
\end{tabular}

above $0.17 \mu \mathrm{mol} \cdot \mathrm{l}^{-1}$ had zero or near-to-zero scores throughout the two inquiries. The five highest U-Al concentrations were found in this subgroup. All of the elevated scores were found at U-AI levels between 1.9 and $3.0 \mu \mathrm{mol} \cdot \mathrm{l}^{-1}$.

\section{Neurological morbidity}

There were no remarkable neurological diseases. Three subjects had infrequent paroxysmal headaches of the migraine type. Two had experienced a cerebral concussion without any neurological sequelae. One person had a history of vasovagal syncope, but the neurological examinations were normal. These illnesses had no association with the aluminum exposure, neither were the subjective symptoms associated with the exposure.

\section{Neurophysiological findings}

The QEEG power parameters recorded from the frontal and frontotemporal regions of the brain correlated with the exposure parameters (table 3 and figure 1). The S-Al level correlated negatively with the average frontal absolute alpha power (figure 2). In addition, weaker positive correlations were observed with the absolute delta and theta power values of the frontal area (table 3 ). The absolute power values from other brain regions did not correlate with the aluminum exposure.
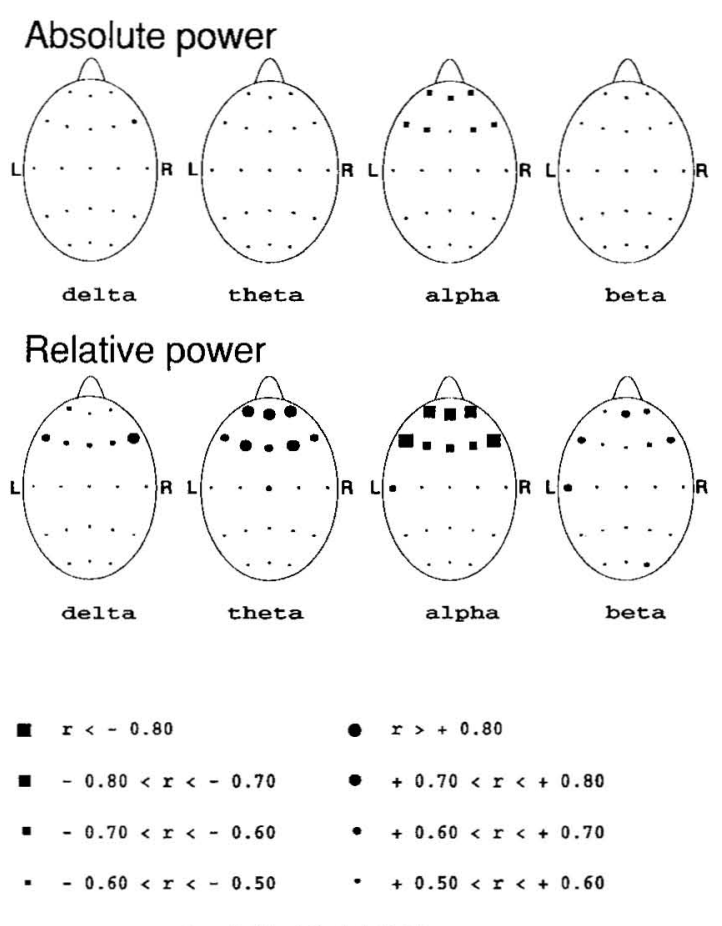

Figure 1. Correlations of serum aluminum (S-Al) with the absolute and relative power values in the quantitative electroencephalography. $(\mathrm{L}=$ left side and $\mathrm{R}=$ right side in the head figures) 
The average frontal relative alpha power correlated negatively with the S-Al content. The relative delta, theta, and beta powers in the frontal region had a positive correlation with the S-Al (table 3 ). Correlations between the U-Al level and the EEG variables showed similar trends, but were weaker and not statistically significant.

The P300 parameters did not correlate with the exposure level.

\section{Discussion}

The examined group was small but homogeneous with respect to education and job qualification. Age did not correlate with the exposure. There was a modest, but still sufficient variation of aluminum in the urine and serum, but no variation of the exposure time. These features made the material suitable for exposure-effect analysis.

\section{Neuropsychological exposure-effect associations}

The welders were found to be a selected group of workers showing good performance in the psychological tests, notably in those requiring intact psychomotor, visual, and spatial function. However, associations of the memory tests and the evenness of the visual reaction times with the aluminum parameters suggested a slight neurotoxic effect on shortterm memory, learning, and attention. The memory impairment was more related to the $\mathrm{U}-\mathrm{Al}$ than to the $\mathrm{S}$-Al concentrations, whereas the reverse was true for the unevenness of the reaction times.

For our studied welders the mean S-Al concentration was $0.21 \mu \mathrm{mol} \cdot \mathrm{l}^{-1}$ and the mean $\mathrm{U}-\mathrm{Al}$ concentration was $2.8 \mu \mathrm{mol} \cdot 1^{1}$. These values were 3.5 and 8.5 times higher than the respective concentrations in an occupationally unexposed reference population (11). For uremic patients with clinical chronic dialysis encephalopathy, plasma aluminum has typically been $3.7-7.4 \mu \mathrm{mol} \cdot \mathrm{l}^{-1}(12)$. Symptomless patients showing impaired attention and impaired visual and motor coordination, impaired information processing, and impaired memory had a mean S-Al of $2.2 \mu \mathrm{mol} \cdot 1^{-1}(2)$. Thus frank neurotoxicity by aluminum in renal patients has been associated with far higher aluminum levels than those found in our subjects. Some recent studies concerning occupational aluminum exposures are more relevant in this context.

Hosovski et al (6) studied 87 aluminum foundry workers who had been exposed to high concentrations of aluminum fumes and dusts for at least six years. Compared with 60 matched workers, the exposed workers had lower scores in tests for memory and psychomotor ability and in tests related to emotional instability. The impairments were of modest intensity, and there were no differences in the intelligence measures. More pronounced neurobehavioral defects - with still average or low average in-

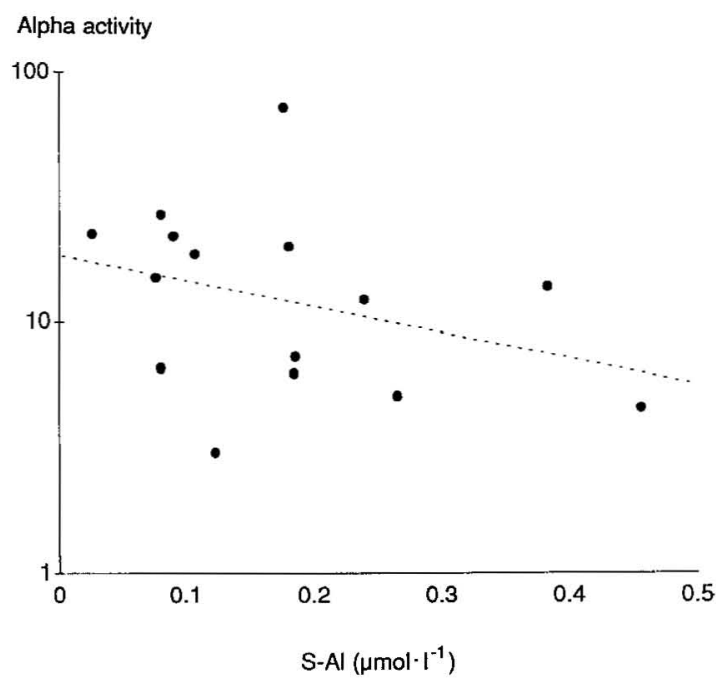

Figure 2. Association between serum aluminum (S-Al) and the average frontal absolute alpha activity $(r=-0.58, P=0.03$, $\mathrm{N}=15$ ).

telligence - were found in 25 symptomatic workers who had been employed in an aluminum smelting plant for $12-23$ years (7). The contribution of other toxic agents could not be excluded, but aluminum was considered the most likely cause. Rifat et al (5) gave three cognitive state tests to 631 miners who had been exposed between 1944 and 1979 for 10 min daily to McIntyre powder (finely ground aluminum and aluminum oxide) in the air of changing rooms; the substance was used as a means of prophylaxis against silicosis. Compared with unexposed miners, the exposed ones had more test scores in the impaired range. A statistically significant difference was found between those exposed for at least 10 years and the referents; the frequency of low scores increased with the duration of exposure. Unfortunately, the S-Al and U-Al concentrations were not measured, but, according to retrospective calculations, the annual alveolar burden of aluminum accumulated by the exposed miners would have been approximately $375 \mathrm{mg}$. Sjögren et al (13) observed that aluminum welders with at least a 13-year exposure history and estimated U-Al levels of $9.2 \mu \mathrm{mol} \cdot \mathrm{l}^{-1}(14)$ reported concentration difficulties and depression twice as frequently as welders working with steel.

While the welders in this study seem to have accumulated an aluminum body burden that is only about one-third of that in the previous Swedish group of welders (the duration of exposure was also onethird), a crude calculation of the annual alveolar burden of aluminum (mean concentration of respirable aluminum being $1.4 \mathrm{mg} \cdot \mathrm{m}^{-3} ; 30 \%$ alveolar retention) would give approximately $1000 \mathrm{mg}$, and thus the cumulative alveolar burden over four years would match the corresponding burden in the miners over 10 years. 
Because of the small sample size in our study the statistical significances of the exposure-effect associations were rather modest, and the results are only suggestive. However, the type of neuropsychological impairment observed tallies with the previous documentation. Aluminum-induced impairment of memory, learning, and attention, and also the underlying neurobiological changes, have been well established in animal studies $(4,15)$. Memory tests were among the tests showing behavioral impairment in clinically normal dialysis patients (2), and memory was the most affected cognitive function in the studies of Hosovski et al (6) and White et al (7). However, the scope of impairments was wider in these studies than in our welder group, which had a considerably lower and shorter exposure.

Poor memory and deficient attention (or executive function) are also the earliest and most consistent symptoms of Alzheimer's disease $(16,17)$. In that respect, our result tallies with previous observations concerning similarities of aluminum-induced changes with Alzheimer's disease. But the similarity of behavioral impairments does not, of course, imply that similar neurobiological changes are operative, nor does it imply a similar prognosis.

\section{Subjective symptoms and moods}

Previous studies suggested affective disturbances in connection with prolonged aluminum exposure $(6,7$, 13). We found a negative association between mood disturbances and $\mathrm{S}-\mathrm{Al}$, which was contrary to expectation and hard to explain in any meaningful way. One hypothesis might be that those welders (in this particular group) who were least prone to experience, or to express, adverse effects were more work-oriented and perhaps less safety-oriented than the others, this attitude leading to higher exposure.

\section{Quantitative electroencephalography}

Increased slow activity, maximally in the frontal areas, and bilateral spike and wave complexes are typical EEG findings among patients with dialysis encephalopathy (18-22), and the severity of the EEG abnormalities correlates with the S-Al levels (19). Progressive slowing of the background activity is an early finding and usually antedates the neurological symptoms (21). These EEG findings, in combination with typical clinical features, have been considered as diagnostic in dialysis encephalopathy $(18,20)$. For mice, oral administration of single doses of aluminum hydroxide, which doubled to tripled the brain aluminum content, induced a dose-dependent diminution of the power of the $7.5-12 \mathrm{~Hz}$ frequency band in QEEG (23). The authors proposed that this acute effect by the aluminum ion may be, at least partly, pharmacological and therefore reversible. As far as we know, no studies have been published concerning EEG findings from occupationally exposed human subjects with normal renal function. In the present study, the welders with higher levels of S-Al had more slow (delta and theta) activity and less alpha activity in the frontal area as compared with welders with lower levels of S-Al. These results are principally consistent with the findings from patients with aluminum encephalopathy and from animal experiments, and they suggest that aluminum uptake from welding may have an effect on cerebral functioning.

\section{Concluding remarks}

Although our study does not allow any definitive conclusions, it suggests that aluminum welding may involve essential hazards for the function of the central nervous system. Disturbances of memory and attention seem to be the most likely early effects; they should be further investigated in more powerful studies.

\section{Acknowledgments}

We are greatly indebted to the occupational health and safety personnel of Finnyards Ltd (formerly HolIming Ltd) (Ms R Tuomola, Dr R Salo, Mr H Pulli, $\mathrm{Mr} \mathrm{K}$ Korsman) and the volunteer welders for their unfailing commitment to the study. Ms A Peltomaa assisted in the neuropsychological examinations. Ms $\mathrm{R}$ Velin made the QEEG recordings and Ms A Lindell performed the aluminum analyses.

The study was financially supported by the Finnish Work Environment Fund.

\section{References}

1. Editorial. Lancet $1992 ; 339: 713-4$.

2. Altman P, Hamon C, Blair J, Dhanesha U, Cunnigham J, Marsh F. Disturbance of cerebral function by aluminum in haemodialysis patients without overt aluminum toxicity. Lancet $1989 ; 2: 7-12$.

3. Banks WA, Castin AJ. Aluminum-induced neurotoxicity: alterations in membrane function at the bloodbrain barrier. Neurose Biobehav Rev 1989;13:47-53.

4. Yokel RA, Provan SD, Meyer JJ, Cambell SR. Aluminum intoxication and the victim of Alzheimer's disease: similarities and differences. Neurotoxicology 1988;9:429-42.

5. Rifat SL, Eastwood MR, Crapper McLachlan DR, Corney PN. Effects of exposure of miners to aluminum powder. Lancet 1990;336:1162-5.

6. Hosovski E, Mastelica Z, Sunderic D, Dadulovic D. Mental abilities of workers exposed to aluminum. Med Lav 1990;81:119-23.

7. White DM, Longstreth WT Jr, Rosenstock L, Claypoole HJ, Brodkin CA, Townes BD. Neurologic syndrome in 25 workers from an aluminum smelting plant. Arch Intern Med 1992;152:1443-8.

8. Aitio A, Riihimäki V, Valkonen S. Aluminum. In: World Health Organization (WHO). Guidelines on biological monitoring of chemical exposure at the workplace. Geneva: WHO. In press.

9. Gamberale F, Iregren A, Kjellberg A. SPES: the computerized Swedish performance evaluation system. Stockholm, Arbetarskyddsverket, 1989. Arbete och hälsa 1989:6. 
10. Hänninen $H$, Lindström $K$. Neurobehavioral test battery of the Institute of Occupational Health. Helsinki: Institute of Occupational Health, 1989.

11. Valkonen S, Riihimäki V, Aitio A. Biological monitoring of occupational exposure to aluminum. In: 14th Nordic atomic spectroscopy and trace element conference: abstracts. In press

12. Alfrey AC, Froment DC. Dialysis encephalopathy. In: De Broe ME, Coburn LW, editors. Aluminum and renal failure. Dordrecht, Boston, London: Kluwer Academic Publishers 1990:249-57.

13. Sjögren B, Gustavsson P, Hogstedt C. Neuropsychiatric symptoms among welders exposed to neurotoxic metals. Br J Ind Med 1990;40:704-7.

14. Sjögren B, Elinder C-G. Nordiska Expertgruppen för Gränsvärdesdokumentation 105: aluminum. Stockholm, Arbetarskyddsverket, 1992. Arbete och hälsa 1992:45.

15. Petit TL. The neurobiology of learning and memory: elucidation of the mechanisms of cognitive dysfunction. Neurotoxicology 1988;9:413-28.

16. Baddeley A, Della Sala S, Spinner H. The two-component hypothesis of memory deficits in Alzheimer's disease. J Clin Exp Neuropsychol 1991;13:372-80.

17. Becker JT. Working memory and secondary memory deficits in Alzheimer's disease. J Clin Exp Neuropsy- chol 1988;10:739-53.

18. Hughes JR, Schreeder MT. EEG in dialysis encephalopathy. Neurology 1980;30(11):1148-54.

19. Ladurner G, Wawschinek O, Pogglitsch H, Petek W, Urlesberger $\mathrm{H}$, Holzer $\mathrm{H}$. Neurophysiological findings and serum aluminum in dialysis encephalopathy. Eur Neurol 1982;21(5):335-9.

20. Lederman RJ, Henry CE. Progressive dialysis encephalopathy. Ann Neurol 1978;4(3):199-204.

21. Mahurkar SD, Smith EC, Mamdani BH, Dunea G. Dialysis dementia - the Chicago experience. J Dial 1978;2:447-58.

22. Rovelli E, Luciani L, Pagani C, Albonico C, Colleoni C, D'Amigo G. Correlation between serum aluminum concentration and signs of encephalopathy in a large population of patients dialyzed with aluminum-free fluids. Clin Nephrol 1988;29(6):294-8.

23. Cutrufo C, Caroli S, Delle Femmine P, Ortolani E, Palazzesi S, Violante N, et al. Experimental aluminum encephalopathy: quantitative EEG analysis of aluminum bioavailability. J Neurol Neurosurg Psychiatry $1984 ; 47: 204-6$.

Received for publication: 10 April 1993 